\title{
UPAYA MENINGKATKAN HASIL BELAJAR SISWA KELAS IV MELALUI METODE TUTOR SEBAYA MATA PELAJARAN BAHASA INDONESIA SD NEGERI 163081 TEBING TINGGI
}

\author{
Sadauhur Sipayung \\ Surel: sadauhurspd@gmail.com
}

\begin{abstract}
ABSTRAK
Metode Tutor Sebaya merupakan salah satu pembelajaran teman atau tutor sebaya yang terpusat pada siswa, dalam hal ini siswa belajar dari siswa lain yang memiliki status umur, kematangan atau harga diri yang tidak jauh berbeda dari dirinya sendiri. Melalui metode ini siswa di ajak secara langsung ke dalam proses melalui latihan-latihan dengan menekankan partisipasi aktif, menjalin kerjasama yang baik, menghargai pendapat orang lain dan bersemangat dalam proses belajar. Pembelajaran tutor sebaya di SD Negeri 163081 ini untuk meningkatkan kualitas, efisian dan efektivitas pembelajaran di kelas.
\end{abstract}

Kata Kunci : Hasil Belajar, Kooperatif, Tutor Sebaya

\section{PENDAHULUAN}

Bahasa memiliki peran
sentral dalam perkembangan
intelektual, sosial, dan emosional
peserta didik dan merupakan
penunjang keberhasilan dalam
mempelajari semua bidang studi.
Pembelajaran bahasa diharapkan
membantu peserta didik mengenal
dirinya, budayanya, dan budaya
orang lain,

Berdasarkan dari hasil pengamatan penulis, masih banyak siswa yang mendapat nilai dibawah rata-rata keteria ketuntasan minimal (KKM) hal ini terlihat dari hasil ulangan harian bahasa indonesia kelas VI SD Negeri 163081 T/P 2015/2016 Tebing Tinggi yang dilakukan dengan 36 siswa yang mengerjakan tugas hanya 12 siswa yang mampu menjawab dengan benar ini berarti hanya 33\% siswa dari 36 orang yang dinyatan tuntas. Sedangkan $67 \%$ siswa dari 36 oang yang dinyatakan belum tuntas.

Identifikasikan

beberapa

permasalahan sebagai berikut :

1. Motivasi belajar bahasa Indonesia siswa masih rendah.

2. Siswa kurang menghargai pentingnya pelajaran bahasa Indonesia.

Berdasarkan identifikasi permasalahan di atas, maka penulis akan melakukan penelitian untuk melihat aktivitas dan hasil belajar Bahasa Indonesia siswa kelas IV SD Negeri 163081 Kota Tebing Tinggi melalui model pembelajaran tutor sebaya, dengan materi semester 1 (percakapan rumpang).

Rumusan masalah dalam penelitian ini adalah: Apakah melalui Metode PembelajaranTutor Sebaya dapat meningkatkan aktivitas belajar 
bahasa Indonesia siswa kelas kelas IV SD Negeri 163081 Kota Tebing Tinggi?

Tujuan penelitian ini adalah untuk mengetahui hasil belajar Bahasa Indonesia siswa kelas IV SD Negeri 163081 Kota Tebing Tinggi.

\section{METODE PENELITIAN}

Jenis penelitian yang dilaksanakan adalah penelitian tindakan kelas. Tindakan yang diberikan adalah penerapan melalui Metode Tutor Sebaya (Peer Tutor).

Sebagai subjek pada penelitian ini adalah siswa kelas IV SD Negeri 163081 Kota Tebing Tinggi yang berjumlah 36 orang terdiri dari 15 orang siswa laki - laki dan 21 orang siswa perempuan.

Penelitian ini direncanakan akan dilaksanakan pada semester 1 tahun pelajaran 2015/2016.

Prosedur penelitian yang digunakan dalam penelitian ini adalah model siklus yang melalui empat tahap yaitu : Perencanaan (Planning), tindakan (Action), observasi (Observation) dan refleksi (Reflection).

Kegiatan yang dilakukan pada tahap perencanaan sebagai berikut:

a. Merancang pembentukan kelompok berpasangan yang terdiri dari 4 orang siswa, secara homogeny.

b. Menyususun kelompok berpasangan, dengan ketentuan membagi setiap kelompok diwakili 2 orang siswa yang tampil sebagai tutor.

c. Merancang Lembaran Kerja Siswa (LKS) yang akan digunakan siswa dalam belajar kelompok.

Tahap tindakan yang akan dilaksanakan dalam kegiatan pembelajaran Metode Tutor Sebaya adalah sebagai berikut :

1. Menjelaskan tujuan pembelajaran yang akan dicapai.

2. Menyampaikan informasi yang berkaitan dengan aturan bekerja yang berlaku pada pembelajaran Metode Tutor Sebaya.

3. Membagikan lembar kerja siswa (LKS).

4. Menyuruh siswa mengerjakan LKS dengan Metode Tutor Sebaya.

5. Pada saat kegiatan belajar mengajar berlangsung, ada beberapa kegiatan yang dilakukan guru yaitu :

a. Guru berkeliling mengamati kegiatan yang dilakukan setiap kelompok.

b. memberikan bimbingan bila ada siswa yang bertanya atau menemukan kesulitan dalam menyelesaikan LKS.

6. Setelah kegiatan belajar mengajar selesai, maka pada kegiatan selanjutnya guru mengambil secara acak kelompok belajar untuk menyampaikan hasil diskusi/kerja mereka, kelompok lain sebagai penanggap. 
Sadauhur Sipayung: Upaya Meningkatkan ..

7. Guru menanggapi hasil presentasi kelompok yang tampil, bila diperlukan guru memberikan klarifikasi terhadap hasil kelompok yang tampil.

8. Menutup pelajaran dan bersamasama siswa menyimpulkan materi pelajaran saat itu.

9. Guru memberikan nilai dan pujian kepada kelompok yang

aktif dan dapat menyelesaikan LKS dengan benar

Tahap observasi adalah melakukan pengamatan terhadap efek dari tindakan yang diberikan untuk melihat dan mendokumentasikan pengaruhpengaruh yang diakibatkan oleh tindakan tersebut.

Tabel 1: Indikator Keberhasilan

\begin{tabular}{|c|c|c|}
\hline No & Indikator /variable & Keterangan \\
\hline a. & $\begin{array}{l}\text { Variabel keaktifan ada } 4 \text {, jika variabel itu } \\
\text { ada diberi nilai } 1 \text { jika tidak ada di beri nilai } \\
0 \text {, indikator keberhasilan tercapai jika } \\
\text { siswa yang mendapat nilai } \geq 3 \text { minimal ada } \\
70 \%\end{array}$ & $\begin{array}{l}\text { 1. Aktif bertanya } \\
\text { 2. Aktif diskusi } \\
\text { 3. Aktif menjawab } \\
\text { 4. Aktif mengerjakan tugas }\end{array}$ \\
\hline b. & $\begin{array}{l}\text { Variabel ketrampilan ada } 6 \text {, jika ada diberi } \\
\text { nilai } 1 \text { jika tidak ada diberi nilai } 0 \text {, } \\
\text { indikator keberhasilan tercapai jika siswa } \\
\text { yang mendapat nilai } \geq 4 \text { minimal ada } 70 \% \\
\text { dari jumlah siswa. }\end{array}$ & $\begin{array}{l}\text { 1. terampil menyiapkan tugas } \\
\text { 2. terampil mengerjakan soal } \\
\text { 3. terampil memecahkan } \\
\text { masalah } \\
\text { 4. terampil bekerja sama } \\
\text { 5. terampil beraptasi dengan } \\
\text { teman } \\
\text { 6. terampil mengambil } \\
\text { keputusan }\end{array}$ \\
\hline c. & $\begin{array}{l}\text { Hasil Belajar Tuntas jika jumlah siswa } \\
\text { yang mencapai nilai tuntas minimal ada } \\
65 \% \text { dari jumlah siswa }\end{array}$ & $\begin{array}{l}\text { Disesuaikan dengan rencana } \\
\text { pembelajaran. }\end{array}$ \\
\hline
\end{tabular}

Tahap refleksi ini bertujuan untuk memberikan informasi mengenai proses pembelajaran dengan Metode Tutor Sebaya (PEER TOTOR).

\section{Teknik Pengumpulan Data}

Teknik pengumpulan data yang digunakan dalam penelitian ini adalah melalui pengamatan dengan mengisi lembar observasi, angket dan pemberian tes hasil belajar.

a. Untuk mengetahui aktivitas siswa selama proses pembelajaran berlangsung,

Sadauhur Sipayung: Upaya Meningkatkan .. guru menyampaikan inıorması.

b. Pemberian angket bertujuan untuk mendapatkan informasi 
tentang sikap siswa terhadap pembelajaran Bahasa Indonesia dengan menggunakan Metode Tutor Sebaya (PEER TOTOR) Angket diberikan di akhir siklus.

c. Tes hasil belajar digunakan untuk mengetahui peningkatan hasil belajar setelah berlangsung proses pembelajaran. Tes yang dimaksud adalah tes hasil belajar yang menyangkut ranah kognitif yang diadakan pada akhir siklus.

\section{Teknik Analisis Data}

Teknik analisis data yang digunakan adalah :

a. Untuk data aktivitas siswa diolah secara kuantitatif dengan menghitung persentasenya, dengan menggunakan rumus yang dikemukakan oleh Anas Sudijono (1997) sebagai berikut:

$P=\frac{F}{N} x 100 \%$

Keterangan :

$\mathrm{P}=$ Presentase

$\mathrm{F}=$ Frekuensi aktivitas belajar siswa

$\mathrm{N}=$ Jumlah siswa seluruhnya

Selanjutnya berdasarkan prosentase yang diperoleh, maka kriteria aktivitas siswa menurut Dimyati dan Mudjiono (2006:125) sebagai berikut :

$1-25 \%$ : Sedikit sekali

$26-50 \%$ : Sedikit

$51-75 \%$ : Banyak

$76-99 \%$ : Banyak sekali

b. Untuk data sikap siswa yang diperoleh dari lembar kuesioner (angket) dianalisis dengan menggunakan rumus yang dikemukakan oleh Nana Sudjana (1995) yaitu :

$$
P=\frac{f}{N} x 100 \%
$$

Dimana :

$\mathrm{P}=$ Angka Presentase

$\mathrm{f}=$ Frekuensi Jawaban

$\mathrm{N}=$ Jumlah Responden

c. Untuk data hasil belajar dianalisis dengan melihat ketuntasan hasil belajar siswa secara individual.

Tingkat penguasaan hasil belajar dapat dihitung dengan menggunakan rumus sebagai berikut :

$$
N I=\frac{T}{S M} x 100 \%
$$

Dimana :

$$
\begin{aligned}
& N I=\text { Ketuntasan Belajar Individu } \\
& T=\text { Skor Yang Diperoleh Siswa } \\
& S M=\text { Skor Maksimum Tes }
\end{aligned}
$$

\section{HASIL DAN PEMBAHASAN}

Sesuai dengan rancangan penelitian pembelajaran dilaksanakan berdasarkan rancangan pembelajaran yang sesuai dengan silabus dan Rencana Pelaksanaan Pembelajaran (RPP). Pembelajaran yang dilaksanakan adalah meggunakan model pembelajaran Metode Tutor Sebaya dengan menggunakan bantuan Lembar Kerja Siswa (LKS). Sesuai dengan rancangan penelitian, peneliti merencanakan siswa dibagi kedalam kelompok yang terdiri dari 4 orang. Sebelumnya peneliti membagi siswa 
Sadauhur Sipayung: Upaya Meningkatkan ..

atas 9 kelompok (setiap kelompok diwakili siswa yang memiliki kemampuan akademik), dengan cara siswa diurutkan berdasarkan kemampuan akademik, kemudian dibagi 9, yang masing - masing terdiri dari 4 orang.

\section{Tabel 2 : Keaktifan Siswa Siklus 1}

\begin{tabular}{|c|c|c|c|}
\hline No & Keaktifan & $\begin{array}{c}\text { Jumlah } \\
\text { siswa }\end{array}$ & $\begin{array}{c}\text { Prosentase } \\
\%\end{array}$ \\
\hline 1 & $\begin{array}{l}\text { Aktif } \\
\text { bertanya }\end{array}$ & & $3611 \%$ \\
\hline 2. & Aktif diskusi & 20 & $55,60 \%$ \\
\hline 3. & $\begin{array}{l}\text { Aktif } \\
\text { menjawab }\end{array}$ & 10 & $27,22 \%$ \\
\hline 4. & $\begin{array}{l}\text { Aktif } \\
\text { mengerjakan } \\
\text { tugas }\end{array}$ & 7 & $19,44 \%$ \\
\hline & Rata rata & & $34,59 \%$ \\
\hline
\end{tabular}

Tabel 3 : Skor Keaktifan Individu Siklus 1

\begin{tabular}{|c|c|c|c|c|}
\hline No & $\begin{array}{l}\text { Katagori } \\
\text { keaktifan }\end{array}$ & Skor & $\begin{array}{c}\text { Jumlah } \\
\text { siswa }\end{array}$ & Prosentese \\
\hline 1. & $\begin{array}{c}\text { Aktif } \\
\text { Cukup }\end{array}$ & 4 & 10 & $27,78 \%$ \\
\hline 2. & aktif & 3 & 14 & $38,90 \%$ \\
\hline 3. & Kurang & 2 & 12 & $33,33 \%$ \\
\hline 4. & $\begin{array}{c}\text { aktif } \\
\text { Tidak aktif }\end{array}$ & 1 & 2 & $5,60 \%$ \\
\hline
\end{tabular}

Tabel : 4 Keterampilan Proses Siklus 1

\begin{tabular}{|c|c|c|c|}
\hline No & $\begin{array}{c}\text { Katagori } \\
\text { Keterampilan }\end{array}$ & $\begin{array}{c}\text { Jumlah } \\
\text { siswa }\end{array}$ & $\%$ \\
\hline $\begin{array}{l}1 . \\
2 . \\
3 . \\
4 . \\
5 . \\
6 .\end{array}$ & $\begin{array}{l}\text { Terampil } \\
\text { menyiapakan tugas } \\
\text { Terampil } \\
\text { mengerjakan soal } \\
\text { Terampil } \\
\text { memecahkan masalah } \\
\text { Terampil bekerja } \\
\text { sama } \\
\text { Terampil beradaptasi } \\
\text { dengan teman } \\
\text { Terampil mengambil } \\
\text { kesimpulan }\end{array}$ & $\begin{array}{l}15 \\
11 \\
14 \\
25 \\
23 \\
18\end{array}$ & $\begin{array}{c}69,44 \% \\
30,56 \% \\
38,89 \% \\
69,44 \% \\
63,89 \% \\
50 \%\end{array}$ \\
\hline & Rata-rata & & $53,70 \%$ \\
\hline
\end{tabular}

Tabel 5 : Skor Keterampilan Individu Siklus 1

\begin{tabular}{|l|l|l|c|l|}
\hline No & $\begin{array}{l}\text { Katagori } \\
\text { keterampilan }\end{array}$ & Skor & $\begin{array}{l}\text { Jumlah } \\
\text { siswa }\end{array}$ & Prosentase \\
\hline 1. & Terampil & 5 & 8 & $22,22 \%$ \\
2. & Cukup & dan & 13 & $36,11 \%$ \\
3. & terampil & 6 & 10 & $27,78 \%$ \\
4. & Kurang & 4 & 5 & $13,90 \%$ \\
& terampil & 3 & & \\
& Tidak terampil & 1 & & \\
& & dan & & \\
& & 2 & & \\
\hline
\end{tabular}

Tabel 6 : Hasil Belajar Siswa Siklus 1

\begin{tabular}{|l|l|l|l|l|}
\hline $\begin{array}{l}\text { Jumlah } \\
\text { siswa }\end{array}$ & $\begin{array}{l}\text { Nilai } \\
\text { rata } \\
\text { rata- }\end{array}$ & $\begin{array}{l}\text { Hasil } \\
\text { Nilai } \geq 70\end{array}$ & $\begin{array}{l}\text { Hasil } \\
\text { nilai } \\
70\end{array}$ & $\begin{array}{l}\text { Nilai } \\
\text { yang } \\
\text { tuntas \% }\end{array}$ \\
\hline 36 & 58,33 & 10 & 26 & $27,78 \%$ \\
\hline
\end{tabular}

Tabel : 7 hasil pengamatan siklus 1

\begin{tabular}{|l|l|l|l|l|}
\hline No & variabel & $\begin{array}{l}\% \\
\text { tuntas }\end{array}$ & $\begin{array}{l}\% \\
\text { tidak } \\
\text { tuntas }\end{array}$ & $\begin{array}{l}\text { Indikator } \\
\text { kebrhasilan }\end{array}$ \\
\hline 1. & Keaktifan & 55,60 & 44,40 & $70,00 \%$ \\
2. & Keterampilan & $\%$ & $\%$ & $70,00 \%$ \\
3. & Hasil belajar & 50,00 & 50,00 & $70,00 \%$ \\
& & $\%$ & $\%$ & \\
& & 27.22 & 72,78 & \\
& & & $\%$ & \\
\hline
\end{tabular}

Pada akhir siklus 1 dilakukan revisi, ternyata pada siklus 1 masih banyak siswa belum tuntas dan mengalami masalah. Pada variabel keaktifan jumlah siswa yang tuntas yaitu: $55,60 \%$, angka tersebut masih jauh dari indikator keberhasilan untuk variabel keaktifan yaitu siswayang tuntas seharusnya minimal mencapai angka $70 \%$ Permasalahan terletak pada partisifasi siswa dalam mengerjakan tugas-tugas terstuktur, mengawali pembelajaran danpelaksanaan pembelajaran. Untuk menaikan keaktifan ini dilakukan 
penyembuhan dengan pendekatan lebih persuasive terhadap anak untuk selalu mengambil peran dalam proses belajar mengajar apapun yang diberikannya kepad kelompok.

Pada variable keterampilan jumlah siswa yang tuntas pada $50,00 \%$ jauh dari angka indicator keberhasilan yaitu siswa yang tuntas untuk variabel keterampilan minimal $70 \%$. Permasalahannya terletak pada siswa saling belum percaya diri dan masih binggung mengikuti strategi yang akan dilaksanakan. Pada variabel hasil belajar jumlah siswa yang mendapat nilai tuntas adalah: $27,22 \%$ masih jauh dari indikator keberhasilan yang dipatok pada angka $70 \%$. Hal ini sebagai dampak kurangnya keaktifan siswa dalam pembelajaran danrendahnya keterampilan siswa permaian peran.

Tabel : 8 Keatifan Siklus 2

\begin{tabular}{|c|c|c|c|}
\hline No & Keaktifan & $\begin{array}{l}\text { Jumlah } \\
\text { siswa }\end{array}$ & Prosentase $\%$ \\
\hline 1. & Aktif bertanya & 28 & $77,78 \%$ \\
\hline 2. & Aktif diskusi & 30 & $83,33 \%$ \\
\hline 3. & $\begin{array}{l}\text { Aktif } \\
\text { menjawab }\end{array}$ & & \\
\hline \multirow[t]{3}{*}{4.} & & 36 & $100 \%$ \\
\hline & $\begin{array}{l}\text { Aktif } \\
\text { mengerjakan } \\
\text { tugas }\end{array}$ & & \\
\hline & Rata rata & & $84,02 \%$ \\
\hline
\end{tabular}

Tabel: 9 Keaktifan Individu Siklus 2

\begin{tabular}{|l|l|l|l|l|}
\hline No & $\begin{array}{l}\text { Katagori } \\
\text { keaktifan }\end{array}$ & Skor & $\begin{array}{l}\text { Jumalah } \\
\text { siswa }\end{array}$ & Prosentese \\
\hline 1. & Aktif & 4 & 24 & $66,67 \%$ \\
2. & Cukup & 3 & 9 & $25,00 \%$ \\
3. & aktif & 2 & 2 & $5,60 \%$ \\
4. & $\begin{array}{l}\text { Kurang } \\
\text { aktif }\end{array}$ & 1 & 1 & $2,78 \%$ \\
& $\begin{array}{l}\text { Tidak } \\
\text { aktif }\end{array}$ & & & \\
\hline
\end{tabular}

Tabel 10: Keterampilan Proses Siklus 2

\begin{tabular}{|l|l|l|l|}
\hline No & $\begin{array}{l}\text { Katagori } \\
\text { Keterampilan }\end{array}$ & $\begin{array}{l}\text { Jumlah } \\
\text { siswa }\end{array}$ & $\begin{array}{l}\text { Persentase } \\
\%\end{array}$ \\
\hline 1 & Terampil & 29 & $80,60 \%$ \\
2. & menyiapakan tugas & 32 & $88,90 \%$ \\
3. & Terampil & 30 & $83,33 \%$ \\
4. & mengerjakan soal & 32 & $88,90 \%$ \\
5. & Terampil & 36 & $100 \%$ \\
6. & memecahkan & 33 & $91,67 \%$ \\
& masalah & & \\
& Terampil bekerja & & \\
& sama & & \\
& Terampil & & \\
& beradaptasi dengan & & \\
& teman & & \\
& Terampil & & \\
& mengambil & & \\
\hline & kesimpulan & & \\
\hline
\end{tabular}

Tabel : 11 Keterampilan Individu Siklus 2

\begin{tabular}{|l|l|l|l|l|}
\hline No & $\begin{array}{l}\text { Katagori } \\
\text { keterampilan }\end{array}$ & Skor & $\begin{array}{l}\text { Jumlah } \\
\text { siswa }\end{array}$ & Prosentase \\
\hline 1. & Terampil & 5 & 24 & $66,67 \%$ \\
2. & Cukup & dan & 9 & $25,00 \%$ \\
3. & terampil & 6 & 2 & $5,56 \%$ \\
4. & Kurang & 4 & 1 & $2,78 \%$ \\
& terampil & 3 & & \\
& Tidak terampil & 1 & & \\
& & dan & & \\
\hline
\end{tabular}

Tabel 12 : Hasil Belajar Siswa Siklus 2

\begin{tabular}{|l|l|l|l|l|}
\hline $\begin{array}{l}\text { Jumlah } \\
\text { siswa }\end{array}$ & $\begin{array}{l}\text { Nilai } \\
\text { rata } \\
\text { rata- }\end{array}$ & $\begin{array}{l}\text { Hasil } \\
\text { Nila70 }\end{array}$ & $\begin{array}{l}\text { Hasil } \\
\text { nilai } \\
\leq 70\end{array}$ & $\begin{array}{l}\text { nilai } \\
\text { yang } \\
\text { tuntas \% }\end{array}$ \\
\hline 36 & 75,00 & 34 & 2 & $94,44 \%$ \\
\hline
\end{tabular}


Yang mendapat nilai tuntas yaitu siswa yang nilainya $\geq 70 \%$ sebanyak 34 orang siswa $(94,44 \%)$ dan kenaikan 24 orang siswa, yang mendapat nilai tidak tuntas yaitu yang nilainya $\leq 77 \%$ sebanyak 2 orang siswa $(5.56 \%)$. Nilai rata-rata yang di peroleh siswa 75,00. Pada siklis 2 hasil pengamatan variabel penelitian peningkatan yang berarti. Presentasi ketuntasandalam variabel keaktifan naik dari $60,88 \%$ menjadi
$84,02 \%$ angka ini sudah melampaui indikator keberhasilan yaitu $70 \%$. Presentasi ketuntasan dalam variabel keterampilan naik dari 53,70\% menjadi 84,02\%. Angka ini sudah melampui indikator keberhasilan yaitu $70 \%$. Dan ketutasan dalam variabel hasil belajar naik dari $27,22 \%$ menjadi $84,02 \%$ angka ini sudah melampui indikator keberhasilan yaitu $70 \%$.

Table 13 : Hasil pengamatan siklus 2

\begin{tabular}{|l|l|l|l|l|}
\hline No & Variable & $\%$ tuntas & $\%$ tidak tuntas & Indikator kebrhasilan \\
\hline 1. & Keaktifan & $91.60 \%$ & $8,40 \%$ & $70,00 \%$ \\
2. & Keterampilan & $88,90 \%$ & $11,10 \%$ & $70,00 \%$ \\
3. & Hasil belajar & $94,44 \%$ & $5,56 \%$ & $70,00 \%$ \\
\hline
\end{tabular}

Setalah diadakan pengamatan pada siklus 1 dan 2 maka dibandingkan hasil pengamatan pada siklus 1 dan 2 pada variabel-variabel yang diamati yaitu keatifan ,keterampilan proses dan hasil belajar. Siswa yang aktif bertanya meningkat dari 13 orang siswa $(36,11 \%)$ manjadi 28 orang siswa $(77,78 \%)$ yang aktif diskusi meningkat dari 20 orang siswa $(55,60 \%)$ mejadi 30 orang siswa $(83,33 \%)$ dan yang aktif menjawab pertanyaan guru meningkat dari 10 orang siswa $(83,33 \%)$ menjadi 20 orang siswa $(75,00 \%)$. Semua siswa yang aktif mengerjakan tugas baik pada siklus 1 dan 2 (100\%) dan ratarata keaktifan siswa naik dari $55,60 \%$ pada siklus 1 naik menjadi $91,60 \%$.

Pembelajaran tutor sebaya dapat meningkatkan keterampilan siswa dalam proses belajar mengajar, hal ini dapat dilihat dari pengamatan pada saat proses belajar mengajar berlangsung. Siswa yang terampil menyiapkan tugas meningkat dari 15 orang siswa $(69,44 \%)$ menjadi 29 orang siswa $(80,60 \%)$ siswa yang terampil mengerjakan soal meningkat dari 11 orang siswa $(30,56 \%)$ menjadi $32(88,90 \%)$, yang terampil memecahkan masalah meningkat dari 14 orang siswa $(38,89 \%)$ menjadi 30 orang siswa $(83,33 \%)$ yang terampil bekerja sama 25 orang siswa $(69,44 \%)$ meningkat)menjadi 32 orang siswa $(88,90 \%)$, yang terampil beradaptasi dengan teman meningkat dari 23 orang siswa $(63,89 \%)$ menjadi 36 orang siswa (100\%) dan yang terampil mengambil keputusan 
meningkat dari 18 orang siswa (50\%) menjadi 33 orang siswa $(91,67 \%)$. Rata-rata keterampilan proses naik dari $(53,70 \%)$ pada siklus 1 menjadi $(53,70 \%)$. Untuk hasil belajar siswa yang mendapat nilai tuntas yaitu 70 pada siklus 1 sebanyak 10 orang siswa $(27,78 \%)$ naik menjadi 34 orang siswa
$(94,44 \%)$ pada siklus 2. Hasil pengamatan pada siklus 1 dan 2 pada variabel-variabel antara lain keaktifan siswa, keterampilan bermain peran dalam tutor sebaya dan hasil belajar menunjukkan hasil sebagai berikut:

Tabel 14 : Hasil Pengamatan Variabel Pada Siklus 2

\begin{tabular}{|l|c|c|c|c|}
\hline No & Variabel & Siklus 1 & Siklus 2 & Indikator keberhasilan \\
\hline 1. & Keaktifan & $55,60 \%$ & $91,60 \%$ & $70 \%$ \\
2. & Keterampilan & $50,00 \%$ & $88,90 \%$ & $70 \%$ \\
3. & Hasil Belajar & $27,22 \%$ & $94,44 \%$ & $70 \%$ \\
\hline
\end{tabular}

Setelah catatan observasi dianalisis ternyata sudah tidak ada masalah yang timbul, secara umum dapat dikatakan tindakan yang dilakukan pada siklus II telah dapat meningkatkan aktivitas dan hasil belajar siswa dalam pembelajaran Bahasa Indonesia. Dari hasil analisis data pada siklus II dapat dimaknai sebagai berikut: terjadi peningkatan aktivitas siswa dalam pembelajaran Bahasa Indonesia. Hasil belajar mengalami peningkatan yang dapat dilihat dari meningkatnya persentase jumlah siswa yang memperoleh nilai ketuntasan individu $\geq 70$. Karena persentase siswa yang memiliki kemampuan untuk memahami materi kalimat rumpang telah sesuai dengan apa yang diharapkan sehingga penelitian ini dianggap berhasil dan selesai dilakukan.

\section{SIMPULAN}

Setelah dilakukan penelitian tindakan kelas, maka berdasarkan hasil observasi dan hasil refleksi dapat disimpulkan bahwa :

1. Pembelajaran dengan menggunakan Metode Tutor Sebaya dapat meningkatkan aktivitas belajar Bahasa Indonesia siswa kelas IV SD Negeri 163081 Kota Tebing Tinggi.

2. Pembelajaran dengan menggunakan Metode Tutor Sebaya dapat meningkatkan hasil belajar Bahasa Indonesia siswa kelas IV SD Negeri 163081 Kota Tebing Tinggi.

Berdasarkan pembahasan dan kesimpulan penelitian ini, dapat diketahui bahwa model pembelajaran Metode Tutor Sebaya yang diterapkan dalam pembelajaran Bahasa Indonesia sangat efektif 
untuk meningkatkan aktivitas dan hasil belajar Bahasa Indonesia siswa. Keunggulan model pembelajaran Metode Tutor Sebayaini lebih terfokus kepada peran, partisipasi dan kontribusi siswa dalam pembelajaran. Langkah-langkah kegiatan dalam model pembelajaran Metode Tutor Sebaya memungkinkan interaksi kelas tumbuh, hidup dan berkembang. Dengan penerapan model pembelajaran Metode Tutor Sebaya dapat menumbuhkan dan memberi peluang kepada siswa dalam mengembangkan dan melatih sikap serta ketrampilan sosial yang bermanfaat bagi kehidupan dan masyarakat.

Dari hasil penelitian ini dapat ditunjukan bahwa respon siswa terhadap penerapan model pembelajaran Metode Tutor Sebayadalam pembelajaran Bahasa Indonesia sangat positif. Hal ini terlihat dalam proses pembelajaran siswa lebih bersemangat dan aktif. Hasil temuan penelitian ini memberikan masukan kepada peneliti, bahwa untuk meningkat efektivitas pembelajaran Bahasa Indonesia perlu menggunakan model pembelajaran ini. Bahasa Indnesia merupakan pelajaran yang dianggap membosankan bagi kebanyakan siswa, oleh karena itu guru perlu menciptakan suasana belajar menyenangkan, adanya kerjasama di antara siswa, sehingga siswa termotivasi dalam belajar.
Berdasarkan kesimpulan hasil penelitian tindakan ini dapat dikemukakan beberapa saran demi perbaikan dan peningkatan kualitas pembelajaran Bahasa Indonesia sebagai berikut :

a. Bagi siswa yang terlibat dalam penelitian ini agar tetap menanamkan sikap positif dalam pembelajaran Bahasa Indonesia yaitu aktif, menjalin kerjasama yang baik, menghargai pendapat orang lain dan bersemangat dalam belajar.

b. Bagi guru Bahasa Indonesia, model pembelajaran Metode Tutor Sebayadapat dijadikan sebagai alternatif untuk meningkatkan aktivitas dan hasil belajar Bahasa Indonesia siswa,dengan memperhatikan hal-hal sebagai berikut:

1) Sebelum diterapkan, agar kepada siswa diberikan penjelasan yang selengkapnya mengenai model pembelajaran ini supaya di dalam penerapannya siswa benarbenar memahami dan bekerja sesuai dengan prosedur atau langkah-langkah.

2) Pengelolaan waktu, pengelolaan kelas, penyajian LKS dan alat peraga sebaiknya benar-benar dirancang dan disesuaikan dengan alokasi waktu yang tersedia. 
3) Dalam pembentukan kelompok (menentukan pasangan) agar diperhatikan keinginan siswa dengan siapa ia ingin dipasangkan, dan sebaiknya pasangan-pasangan tersebut diganti setiap siklus.

\section{DAFTAR RUJUKAN}

Abdillah. 2002. Quantum Teaching. Yogyakarta : Diva Press.

Djamarah, S. B. 2002. Rahasia Sukses Belajar. Jakarta: PT. Rineka Cipta.

Hasim, Zaini, A. 2005. Portofolio dalam Pembelajaran IPS. Bandung: Remaja Rosda Karya.

Hadi, S. 2007. Pengaruh startegi pembelajaran Cooperative Script terhadap keterampilan berpikir kritis, keterampilan meta kognitif, dan kemampuan kognitif biologi pada siswa SMA Laboratorium Universitas Negeri Malang. Malang: Universitas Negeri Malang.

Hamalik. 2009. Cooperative Learning. Bandung: Alfabeta.

Ischak. 2011. Pembelajaran Kooperatif. Yogyakarta: Pustaka Pelajar.
Kunandar. 2008. Langkah Mudah Penelitian Tindakan Kelas. Jakarta: Raja Grafindo Persada.

Sudjana, N. 2010. Penilaian Hasil Proses Belajar Mengajar. Bandung: Remaja Rosda Karya.

Slameto. 2010. Belajar dan FaktorFaktor yang Mempengaruhinya. Jakarta : Rineka Cipta.

Suprijono, A. 2009. Cooperative Learning Teori dan Aplikasi Paikem.Yogyakarta : Pustaka Belajar.

Syah, M. 2000. Psikologi Pendidikan Dengan Suatu Pendekatan Baru. Bandung: Remaja Rosdakarya.

Tuhusya. $2007 . \quad$ Model Pembelajaran. Bandung: Bina Tugas Mandiri.

Vernon, S. Gerlach 2002. Cara Belajar Yang Efisien. Yogyakarta: Gajah mada University Press. 